\title{
Expressão heteróloga da EMA-2 (equi merozoite antigen) de Theileria equi em Pichia pastoris com potencial utilização em imunobiológicos
}

\author{
Heterologous expression of EMA-2 (equi merozoite antigen) of Theileria equi in \\ Pichia pastoris with potential use in immunobiologics
}

\begin{abstract}
Ana Muñoz Vianna, ${ }^{\text {III* }}$ Relber Aguiar Gonçales ${ }^{\text {II }}$ Ana Paula de Souza Stori de Lara ${ }^{\text {II }}$ Luciano da Silva Pinto ${ }^{I}$ Leandro Quintana Nizoli ${ }^{I I I}$ Fábio Pereira Leivas Leite ${ }^{\mathrm{I}}$ III
\end{abstract}

\section{RESUMO}

A piroplasmose equina causada por Theileria equi acomete os equinos de forma endêmica no Brasil e em diversos outros países tropicais e subtropicais. Considerada uma das mais importantes doenças de equinos, causa danos à saúde animal e perdas econômicas. A proteína equi merozoite antigen (EMA-2) é uma das principais proteínas de superfície, expressa nos diversos estágios do ciclo do parasita, estimula resposta imune em animais infectados, tornando-se um possivel candidato para utilização em diagnóstico. O gene EMA-2 foi clonado e expresso na levedura Pichia pastoris. A proteína EMA-2 recombinante (rEMA-2) foi caracterizada antigenicamente por Western Blot e por ELISA indireto, utilizando-se soro de equino positivo para theileriose. O resultado do ELISA demonstrou uma especificidade de 90,9\% e sensibilidade de $83,3 \%$, quando comparado ao padrão, sendo superior à imunofluorescência (80,6\% de especificidade e 75,0\% de sensibilidade), o que sugere que a rEMA-2 expressa em $\boldsymbol{P}$. pastoris é um promissor antígeno para ser utilizado como ferramenta no imunodiagnóstico de theileriose equina.

Palavras-chave: equinos, imunodiagnóstico, piroplasmose, theileriose.

\section{ABSTRACT}

Theileria equi, the causative agent of equine piroplasmosis, is endemic in Brazil and many other tropical and subtropical countries. It is considered one of the most important diseases of horses causing animal health problems and significant economic loss. The Protein equi merozoite antigen-2 (EMA-2) is a major surface protein that is expressed in different parasite cycle stages and induces immune response in infected animals, being a possible candidate to be used in diagnose. EMA-2 gene was cloned and expressed in the yeast Pichia pastoris, and the recombinant protein EMA-2 (rEMA-2) was characterized by Western Blot and indirect ELISA using equine positive sera. The
ELISA results demonstrated a specificity of $90.9 \%$ and a sensitivity of $83.3 \%$ compared to the standard ELISA and being superior to immunofluorescence (80.6\% of specificity and $75.0 \%$ of sensitivity) suggesting that the rEMA-2 expressed in $\boldsymbol{P}$. pastoris is a promising antigen to be used as a tool in immunodiagnostic of theileriasis.

Key words: equines, immunodiagnostic, piroplasmosis, theileriasis.

\section{INTRODUÇÃO}

Theileria equi, anteriormente denominado Babesia equi (MEHLHORN \& SCHEIN, 1998), é um protozoário hemoparasita e agente etiológico de piroplasmose equina (MEALEY et al., 2012). No Brasil, apresenta-se de forma endêmica, levando a significativas perdas econômicas (BALDANI et al., 2011).

A transmissão de T. equi ocorre no repasto do carrapato, inoculando suas formas infectantes (esporozoítos). Uma vez no hospedeiro, os esporozoítos infectam os leucócitos (MEHLHORN \& SCHEIN, 1998) e posteriormente os eritrócitos (UILENBERG, 2006). A transmissão congênita de T. equi também pode ocorrer levando ao aborto ou morte peri natal (HEIM et al., 2007). Os sinais clínicos variam de quadros assintomáticos a agudos (febre, icterícia e anemia). Animais que se recuperam de infecções agudas deixam de apresentar os sintomas e permanecem como reservatórios de $\boldsymbol{T}$. equi, mantendo a doença endêmica (HEIM et al.,

ICentro de Desenvolvimento Tecnológico, Universidade Federal de Pelotas (UFPel), Campus Capão do Leão, CP 354, 96010-900, Pelotas,

RS, Brasil. E-mail: a.munozvianna@gmail.com. *Autor para correspondência.

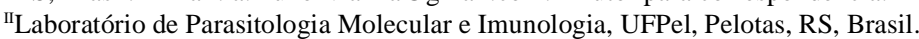

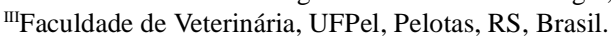


2007). Devido à grande disseminação de ambos, $\boldsymbol{T}$. equi e os diversos carrapatos vetores, o diagnóstico e prevenção desta enfermidade se fazem necessários tanto em áreas endêmicas como em não endêmicas (HUANG et al., 2003).

Theileriose tem sido diagnosticada por diversos métodos, tais como: Esfregaços sanguíneos corados por Giemsa, Teste de Fixação do Complemento (TFC), Teste de Imunofluorescência Indireta (IFAT), Reação em Cadeia da Polimerase (PCR), Ensaio imunoenzimático (ELISA), utilizando lisados do parasito (HUANG et al., 2006), e ELISAs comerciais, utilizando proteínas recombinantes (KNOWLES et al., 1992). Entretanto, alguns destes métodos possuem suas limitações, incluindo baixa sensibilidade descrita para TFC, problema de subjetividade e baixa sensibilidade para o IFAT e preparações complicadas e laboriosas na utilização de antígenos lisados do parasito no ELISA (HUANG et al., 2006).

Segundo a OIE (2010), os métodos prescritos para que se obtenha a permissão para o transporte internacional de equinos são ELISA e o IFAT, sendo o TFC um substituto, portanto os testes sorológicos exercem um papel importante no trânsito desses animais. O IFAT, no entanto, necessita de profissionais experientes para sua realização e detecção da theileriose equina (RAMPERSAD et al., 2003). ELISAs tem sido realizados utilizando diferentes antígenos recombinantes, o que demonstra que pode ser um teste útil para identificação de theileriose em equinos (BALDANI et al., 2011).

Os antígenos de superfície (EMAs- equi merozoite antigen) exercem importante papel na aderência e penetração de $\boldsymbol{T}$. equi nos eritrócitos dos hospedeiros (NIZOLI et al., 2009). São expressos durante os vários estágios do ciclo, tanto no hospedeiro definitivo como no vetor (UETI et al., 2003), tornando-se excelentes alvos na detecção de anticorpos contra este parasita.

Dentre as estratégias utilizadas para a produção de antígenos, utiliza-se a levedura Pichia pastoris, que concilia vantagens na manipulação genética, associada ao crescimento em meios de cultivo simples. Por ser um organismo eucarioto, $\boldsymbol{P}$. pastoris proporciona a expressão de proteínas com modificações pós-traducionais, como glicosilação, além de secretar as proteínas heterólogas de forma solúvel no meio, simplificando etapas de purificação (CEREGHINO \& CREGG, 2000). O presente trabalho teve por objetivo avaliar a proteína EMA-2 recombinante (rEMA-2), expressa em $\boldsymbol{P}$. pastoris, e sua utilização como antígeno em ELISA indireto.

\section{METODOLOGIA}

Linhagens, cultivo e extração de DNA

O DNA de $\boldsymbol{T}$. equi foi extraído conforme o método de MILLER et al. (1988) modificado, utilizando sangue de um equino infectado experimentalmente (cepa UFPel E15) e comprovado por IFAT pelo Laboratório de Doenças Parasitárias da Universidade Federal de Pelotas (UFPel) (NIZOLI et al., 2009).

Amplificação e sequenciamento do gene que codifica EMA-2

A sequência do gene que codifica para a proteína EMA-2 foi amplificada por PCR como descrito: o total do PCR-Mix foi de $25 \mu \mathrm{L}$, contendo $0,5 \mu \mathrm{L}$ de Taq DNA polimerase $(5 \mathrm{U} / \mu \mathrm{L}), 2,0 \mu \mathrm{L} 10 \mathrm{x}$ PCR tampão, $1,5 \mu \mathrm{L} 50 \mathrm{mM} \mathrm{MgCl}_{2}, 0,5 \mu \mathrm{L}$ dNTPs, $0,5 \mu \mathrm{L} 10 \mathrm{pmol} \mu \mathrm{L}^{-1}$ oligoiniciadores anterógrado (5' - CAC CGC GGG GAA TGT TGA GCA A - 3') e oligoiniciadores retrógrado (5' - CCT CTA GAC GGT AGA ACA AAG CAA CGG CG - 3'), $1 \mu \mathrm{L}$ de DNA ( 120ng), obtido como descrito e água estéril para completar o volume da reação. Os oligoiniciadores para EMA-2 foram desenhados utilizando-se o programa Vector NTI a partir das sequências depositadas no GenBank, acesso AB013725. O produto de PCR foi purificado usando-se o kit Real Genomics da Bio America - Hiyield ${ }^{\mathrm{TM}}$ Gel/PCR DNA Minikit. O sequenciamento do gene foi realizado por ACTGene Análises Moleculares Ltda (Centro de Biotecnologia, Universidade Federal do Rio Grande do Sul, Porto Alegre, RS), utilizando o sequenciador automático ABI-PRISM 3100.

\section{Clonagem do gene EMA-2}

Foi feita a digestão do vetor pPICZ $\alpha \mathrm{B}$ e do gene EMA-2 com as enzimas SacII (Biolabs 20.000 $\mathrm{U} \mathrm{mL}^{-1}$ ) e $X B a \mathrm{I}$ (Invitrogen 20.000 $\mathrm{U} \mathrm{mL}^{-1}$ ). Para a ligação do gene $E M A-2$ com o vetor pPICZ $\alpha \mathrm{B}$, procedeu-se segundo o protocolo EasySelect ${ }^{\mathrm{TM}}$ Pichia Expression Kit-Catalog K1740-01 (Invitrogen). O vetor $\mathrm{pPICZ} \alpha \mathrm{B}$ possui sítio para a adição de cauda de seis histidinas (6xHis) na porção carboxi-terminal da proteína (Invitrogen).

Seleção das colônias recombinantes e Expressão da proteína rEMA-2 em $\boldsymbol{P}$. pastoris

Foram preparados os pré-inóculos das colônias transformadas seguindo o protocolo da EasySelect Pichia Expression Kit (Invitrogen) para colônias Mut+ com algumas modificações. Usou-se um volume de meio BMGY de $50 \mathrm{~mL}$ e 
após passou-se para 90mL do meio BMMY. As amostras foram induzidas com $450 \mu \mathrm{L}$ de metanol filtrado para a produção da proteína por $120 \mathrm{~h}$. Ao final da indução, as amostras foram centrifugadas a $10.000 \mathrm{x} \mathrm{g}$ por $10 \mathrm{~min}$, o precipitado foi desprezado e o sobrenadante armazenado. No sobrenadante do cultivo, foi adicionado sulfato de amônio suficiente para atingir $80 \%$ de saturação. O sulfato de amônio foi adicionado ao sobrenadante sob agitação a $4^{\circ} \mathrm{C}$ e mantido por $18 \mathrm{~h}$. Após este período, foi novamente centrifugado a $6.000 \times$ g $15 \mathrm{~min}^{-1} 4^{\circ} \mathrm{C}$ e o precipitado suspendido com $2 \mathrm{~mL}$ de água destilada.

\section{Purificação e quantificação da proteína}

A purificação da proteína recombinante foi realizada por diálise. Utilizou-se uma membrana semipermeável com ponto de corte $12 \mathrm{KDa}$ (Viskase corporation Dry $21 \mathrm{~mm}$ ). A membrana foi acondicionada em frasco contendo $1 \mathrm{~L}$ de água destilada e mantido a $4^{\circ} \mathrm{C}$ sob agitação durante $48 \mathrm{~h}$, sendo que, nas primeiras $12 \mathrm{~h}$, a água foi trocada a cada 2h. Após este período, o material dialisado foi mantido a $-70^{\circ} \mathrm{C}$ para posterior liofilização (Liofilizador L101 - Liptop, Liobras).

Para a quantificação da proteína, seguiuse o protocolo proposto por BRADFORD (1976). Uma amostra de $10 \mathrm{mg}$ da proteína liofilizada foi diluída em $1 \mathrm{~mL}$ de água destilada. O método foi padronizado usando-se uma curva de diluição de Albumina Sérica Bovina 10\% (BSA). A leitura das amostras foi feita em espectrofotômetro TPREADER - Thermo Plate

\section{Western Blot}

Realizou-se um Western Blot segundo SAMBROOK \& RUSSEL (2001). Após eletroforese no gel de poliacrilamida $12 \%$ (SDS-PAGE), a proteína foi transferida para membrana de nitrocelulose (Amershan $^{\mathrm{TM}}$ Hybond $^{\mathrm{TM}}$ - ECL GE Healthcare). Foi utilizado o marcador de proteínas BenchMark ${ }^{\mathrm{TM}}$ Prestained Protein Ladder 250 $\mu \mathrm{L}$ (Invitrogen); $20 \mu \mathrm{L}$ da proteína EMA-2, BSA 10\% (controle negativo). Após bloqueio, a membrana foi incubada com Anti-His C-terminal-HRP AB (Invitrogen), diluída 1:5000 (v/v) em PBS-T. Foi realizado um Western blot, segundo SAMBROOK \& RUSSEL (2001), com soro equino positivo para theileriose (IFAT) na concentração de 1:100 (v/v em salina isotônica com tampão fosfato contendo Tween-20 PBS-T) e, como anticorpo secundário, utilizou-se soro anti-equino conjugado com peroxidase (Sigma) 1:3000. O marcador utilizado foi Precision Plus Protein Dual Color Standards (Bio Rad).

\section{ELISA}

Utilizou-se quarenta e um soros equinos de diferentes origens, porém todos pacientes do hospital da UFPel e testados por IFAT (4 positivos e 37 negativos por IFAT), um soro controle positivo de equino infectado experimentalmente e um soro controle negativo para $\boldsymbol{T}$. equi, retirado de um potro pertencente a rebanho sem histórico para theileriose e testado por PCR, imunofluorescência e ELISA padrão.

$\mathrm{O}$ antígeno rEMA-2 foi aplicado às placas de Poliestireno (Nunc ${ }^{\text {TM}}$-Placa imuno Polysorp - 96 orifícios) na concentração de $200 \mathrm{ng} \mathrm{mL}^{-1}$, diluído em tampão carbonato bicarbonato $\mathrm{pH} 9.6$, por 18 horas a $4^{\circ} \mathrm{C}$. Após três lavagens, bloqueou-se com leite em pó a 5\% em PBS-T. Posteriormente, os controles positivos, negativos e os soros a serem testados foram diluídos em PBS-T na concentração de 1:100 e adicionados em duplicata à placa. Incubou-se a $37^{\circ} \mathrm{C}$ por $90 \mathrm{~min}$ e, após três lavagens, adicionou-se o anti-IgG equino conjugado com peroxidase (Sigma), diluído 1:6000; a placa foi incubada a $37^{\circ} \mathrm{C}$ durante $90 \mathrm{~min}$. Após lavagem, o cromógeno/substrato tampão citrato/fosfato (TPS) foi adicionado e a placa mantida $15 \mathrm{~min}$ no escuro. A reação foi interrompida pela adição de $50 \mu \mathrm{L}_{\text {orifício }}{ }^{-1}$ de $\mathrm{H}_{2} \mathrm{SO}_{4} 1 \mathrm{~N}$. As absorbâncias foram medidas no leitor de micro placas (TP-READER - Thermo Plate), utilizando 492nm de comprimento de onda. Os mesmos soros equinos testados por ELISA com a proteína recombinante e por IFAT foram testados também com kit de ELISA padrão-ELISA competitivo (VMRD. Inc. Babesia equi Antibody Test Kit, cELISA).

Análise estatística

A análise ROC (Receiver Operating Characteristic) foi realizada pelo software estatístico MedCalc, versão 10.3.0.0, www.medcalc.be.

\section{RESULTADOS E DISCUSSÃO}

ELISAs têm sido utilizados no diagnóstico de $\boldsymbol{T}$. equi com a utilização de diferentes antígenos recombinantes, tais como: EMA-1 (KNOWLES et al., 1992; BALDANI et al., 2011), EMA-2 (TANAKA et al., 1999; KUMAR et al., 2013), Be82 (HIRATA et al., 2002) e Be158 (HIRATA et al., 2005), expressos em $\boldsymbol{E}$. coli e baculovírus, o que demonstra que estas proteínas recombinantes podem ser um teste útil para identificação de theileriose em equinos (OIE, 2008). Estudos anteriores mostraram que tanto a proteína EMA-1 quanto EMA-2 são expressas em diferentes estágios do ciclo do parasita extra e intra eritrocitário (KUMAR et al., 2004). Entretanto, EMA-2 é liberada no citoplasma e na membrana deste eritrócito, 
sugerindo ser um dos primeiros antígenos a serem reconhecidos pelo sistema imune (KUMAR et al., 2004, 2013). Recentemente, BHOORA et al. (2010), MUNKHJARGAL et al. (2013), KUMAR et al. (2013) relataram diversidade genética em amostras baseadas no gene da EMA-1, o que poderia alterar a especificidade e sensibilidade de um teste de diagnóstico no qual o antígeno escolhido fosse a EMA-1. Esta diversidade genética ainda não foi reportada em relação à EMA-2. Estas observações nos levaram à escolha da proteína recombinante EMA-2 para o desenvolvimento de nossos estudos. Nossos resultados corroboram os de KUMAR et al. (2013), que, utilizando ELISA com antígeno de EMA-2, apresentaram uma correlação com o ELISA padrão.

Neste trabalho, a proteína EMA-2 foi expressa em $\boldsymbol{P}$. pastoris e apresentou epítopos (sequenciais e/ou conformacionais) que foram reconhecidos por anticorpos presentes nos soros de equinos naturalmente infectados. $\mathrm{O}$ sequenciamento do gene mostrou $99 \%$ de homologia com a sequência depositada no GenBank AB013725.

Segundo CEREGHINO \& CREGG (2000), outras proteínas de superfície de protozoários também foram expressas em $\boldsymbol{P}$. pastoris como Plasmodium falciparum merozoite surface protein 1 (MSP-1) e Plasmodium vivax apical membrane antigen 1 (AMA-1). O sistema de expressão $\boldsymbol{P}$. pastoris que foi utilizado para a expressão da proteína EMA-2 de T. $\boldsymbol{e q u i}$, proporciona um aumento na produção da proteína, se comparada ao sistema $\boldsymbol{E}$. coli, pois as proteínas são secretadas para o meio facilitando sua purificação (HARTWIG et al., 2010).

Western Blot, utilizando anticorpo antihistidina (Figura 1A) e soro de equino naturalmente infectado, (Figura 1B) reconheceram a proteína rEMA-2. A proteína foi avaliada por ELISA com soros de equinos controles (positivo e negativo por IFAT), e foi reconhecida por soros de equinos naturalmente infectados, demonstrando a sua antigenicidade. O kit de ELISA comercial (VMRD. Inc. Babesia equi Antibody Test Kit, cELISA) foi utilizado como padrão para avaliar os resultados com um teste semelhante (KUMAR et al., 2013). Usandose a média da leitura de densidade ótica de ELISA e o ponto de corte estabelecido por análise ROC, os resultados sugerem a possibilidade de diferenciar animais positivos e negativos para theileriose. $\mathrm{Na}$ análise ROC, os pontos de corte basearam-se nos resultados do ELISA padrão. Quando se comparou ELISA teste (placa sensibilizada com a proteína rEMA-2) com ELISA padrão, obteve-se uma especificidade de $90,9 \%$ e sensibilidade de $83,3 \%$ (Figura 2A). KUMAR et al. (2013) obtiveram $97,0 \%$ de sensibilidade e $96,0 \%$ de especificidade ao compararem ELISA desenvolvido com o mesmo teste padrão usado neste trabalho. No presente trabalho, além de um número menor de animais, usou-se o teste estatístico ROC, enquanto KUMAR et al. (2013) analisaram utilizando desvio padrão o que tende a diminuir a acurácia na obtenção dos resultados. Ao se comparar os resultados da presente pesquisa com os de TANAKA et al. (1999), que, realizando ELISA com EMA-2 expressa em baculovírus, também demonstraram diferença entre amostras de soros positivos e negativos de equinos para T. equi. Entretanto, não estudaram especificidade e sensibilidade e não houve comparação com teste padrão.

Ao comparar ELISA padrão ao IFAT, obteve-se uma especificidade de $100 \%$, mas

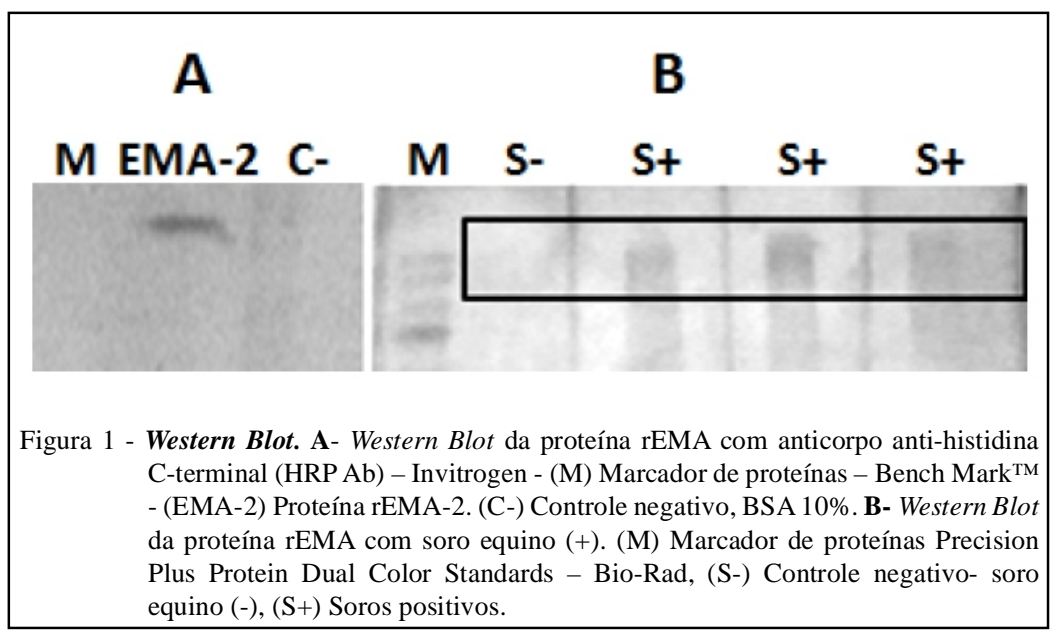

Ciência Rural, v.44, n.10, out, 2014. 

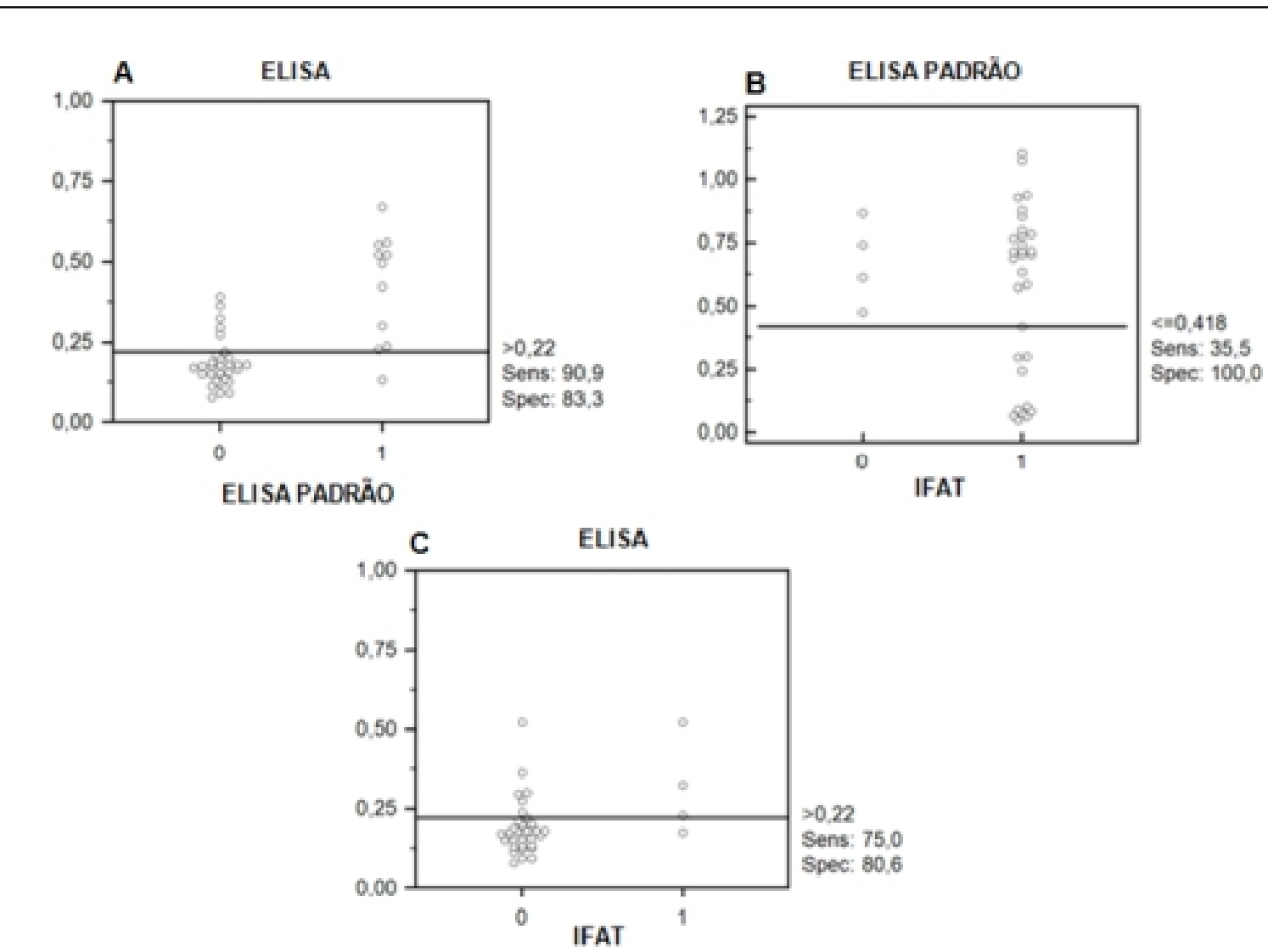

Figura 2 - Análise ROC do ELISA, IFAT comparando com ELISA padrão. (0) Soros negativos, (1) Soros positivos. A - Análise ROC do ELISA com ELISA padrão, identificando ponto de corte $>0,22$. B - Análise ROC do ELISA padrão com IFAT, identificando ponto de corte $>0,418$. C - Análise ROC do ELISA com IFAT, identificando ponto de corte >0,22.

sensibilidade de apenas $35,5 \%$ (Figura 2B). O ELISA teste, ao ser comparado ao IFAT, apresentou especificidade de $80,6 \%$ e sensibilidade de $75 \%$ (Figura 2C). Os resultados obtidos nos apontam a subjetividade do teste de imunofluorescência e a possibilidade de reações cruzadas, devido à sensibilização da lâmina com eritrócitos de equinos infectados com o parasita (NIZOLI et al., 2009).

O presente trabalho ficou limitado pela não realização de testes cruzados com outros hemoparasitas e pelo número de animais estudados. Entretanto, TANAKA et al. (1999), KUMAR et al. (2013), utilizando rEMA-2 como antígeno, em amostras de soros positivas para B. caballi, Trypanosoma evansi, mormo, anemia equina e influenza equina não observaram reações cruzadas. Com um maior número de soros testados, seria possível obter resultados diferentes, quanto aos valores de especificidade e sensibilidade.

\section{CONCLUSÃO}

O estudo demonstrou que a proteína rEMA-2 expressa em $\boldsymbol{P}$. pastoris é um promissor antígeno para utilização em testes de imunodiagnóstico para theileriose equina.

\section{AGRADECIMENTOS}

Agradecemos ao Programa de Pós-Graduação em Veterinária (PPGV) e ao Programa de Pós-Graduação em Biotecnologia (CDTec) e a Coordenação de Aperfeiçoamento de Pessoal de Nível Superior (CAPES) pela concessão de bolsas para A.M.V.

\section{REFERÊNCIAS}

BALDANI, C.D. et al. Production of recombinant EMA-1 protein and its application for the diagnosis of Theileria equi using an enzyme immunoassay in horses from São Paulo State, Brazil. Revista Brasileira Parasitologia Veterinária, v.20, n.1, p.54-60, 2011. Disponível em: <www.scielo.br/pdf/rbpv/v20n1/ 
a11v20n1>. Acesso em: 03 jun. 2013. doi: 10.1590/S198429612011000100011.

BHOORA, R. et al. Sequence heterogeneity i the equi merozoite antigen gene (ema-1) of Theileria equi and development of na ema-1-specific Taq-Man MGB assay for the detection of $\boldsymbol{T}$. equi. Veterinary Parasitology, v.172, n.1-2, p.33-45, 2010. Disponível em: <www.ncbi.nln.nih.gov/pubmed/?term=EMA-1+ and+Bhoora>. Acesso em: 04 fev. 2014. doi: 10.1016/j. vetpar.2010.04.025.

BRADFORD, M. Analytical biochemistry. v.72, p.248-254, 1976. Disponível em: <http://www.ciens.ucv.ve:8080/generador/ sites/lab-bioq-gen/archivos/Bradford\%201976.pdf>. Acesso em: 10 out. 2013

CEREGHINO, J.L.; CREGG, J.M. Heterologous protein expression in the methylotrophic yeast Pichia pastoris. FEMS Microbiology Reviews, v.24, n.1, p.45-66, 2000. Disponível em: <www.ncbi.nlm.nih.gov/pubmed/10640598>. Acesso em: 20 maio 2013. doi: 10.1111/j.1574-6976.2000.tb00532.x.

HARTWIG, D.D. et al. High yield expression of leptospirosis vaccine candidates $\operatorname{LigA}$ and Lig32 in the methylotrophic yeast Pichia pastoris. Microbial Cell Factories, v.9, p.98, 2010. Disponível em: <http://www.microbialcellfactories.com/cont ent/ 9/1/98>. Acesso em: 04 fev. 2014. doi: 10.1186/1475-2859. 9-98.

HEIM, A. et al. Detection and molecular characterization of Babesia caballi and Theileria equi isolates from endemic areas of Brazil. Parasitology Research, v.102, p.63-68, 2007. Disponível em: 〈www.ncbi.nlm.nih.gov/pubmed/17828553>. Acesso em: 03 jun. 2013. doi: 10.1007/s00436-007-0726.

HIRATA, H. et al. Cloning of a truncated Babesia equi gene encoding an 82-kilodalton protein and its potential use in an enzyme-linked immunosorbent assay. Journal of Clinical Microbiology, v.40, p.1470-1474, 2002. Disponível em: <www. ncbi.nlm.nih.gov>. Acesso em: 03 fev. 2014. doi: 10.1128/ JCM.40.4.1470-1474.2002.

HIRATA, H. et al. Cloning of a novel Babesia equi gene encoding a 158-kilodalton protein useful for serological diagnosis. Clinical and Vaccine Immunology, v.12, n.2, p.334-338, 2005. Disponível em: <http://cvi.asm.org/content/12/2/334. short>. Acesso em: 03 fev. 2014. doi: 10.1128/CDLI.12.2.334338.2005 .

HUANG, X. et al. High-Level expression and purification of a truncated Merozoite Antigen-2 of Babesia equi in Escherichia coli and its potential for immunodiagnosis. Journal of Clinical Microbiology, v.41, p.1147-1151, 2003. Disponível em: <www. ncbi.nlm.nih.gov/pubmed/12624044>. Acesso em: 03 jun. 2013. doi: 10.1128/JCM.41.3.1147-1151.

HUANG, X. et al. Evaluation of enzyme-linked immunosorbent assays with recombinant antigens for the serodiagnosis of equine Babesia infections. Veterinary Parasitology, Short communication, 2006. Disponível em: <www.ncbi.nlm.nih.gov/ pubmed/16621293>. Acesso em: 03 jun. 2013. doi: 10.1016/j. vetpar.2006.03.013.

KNOWLES, D.P. et al. Antibody to a recombinant merozoite protein epitope identifies horses infected with Babesia equi Journal of Clinical Microbiology, v.30, p.3122-3126, 1992.
Disponível em: 〈http://jcm.asm.org/content/30/12/3122〉. Acesso em: 31 jan. 2013

KUMAR, S. et al. Expression of Babesia equi EMA1 and EMA-2 during merozoite developmental stages in erythrocyte and their interaction with erythrocytic membrane skeleton. Molecular and Biochemical Parasitology, v.133, p.221-227, 2004. Disponível em: <www.ncbi.nim.nih.gov/ pubmed/14698434>. Acesso em: 08 out. 2013. doi: 10.1016/j. molbiopara.2003.10.010.

KUMAR, S. et al. Development of EMA-2 recombinant antigen based enzyme-linked immunosorbent assay for seroprevalence studies of Theileria equi infection in Indian equine population. Veterinary Parasitology, v.198, p.10-17, 2013. Disponível em: <www.sciencedirect.com/science/article/pii/ S0304401713004949>. Acesso em: 01 fev. 2014. doi: 10.1016/j. vetpar.2013.08.030

MEALEY, R.H. et al. Protective effects of passively transferred merozoite-specific antibodies against Theileria equi in horses with severe combined immunodeficiency. Clinical and Vaccine Immunology, v.19, n.1, p.100-104, 2012. Disponível em: <www. ncbi.nlm.nih.gov/pubmed/22038847>. Acesso em: 20 maio 2013. doi: 10.1128/CVI.05301-11.

MEHLHORN, H.; SCHEIN, E. Redescription of Babesia equi Laveran, 1901 as Theileria equi Mehlhorn, Schein 1998. Parasitology Research, v.84, p.467-475, 1998. Disponível em: <http://link.springer.com/article/10.1007/ s004360050431\#page-1>. Acesso em: 20 maio 2013. doi: $10.1007 / \mathrm{s} 004360050431$.

MILLER, S.A. et al. A simples salting out procedure for extracting DNA from human nucleated cells. Nucleic Acids Research, v.6, p.1215, 1988. Disponível em: <http://www.ncbi.nlm.nih.gov/pmc/ articles/PMC334765/>. Acesso em: 3 maio 2013. doi: 10.1093/ nar/16.3.1215.

MUNKHJARGAL, T. et al. Prevalence and genetic diversity of equine piroplasms in Tov province, Mongolia. Infection Genetic Evolution, v.16, p.178-185, 2013. Disponível em: <www.ncbi. nln.nih.gov/pubmed/23416256>. Acesso em: 04 fev. 2014. doi: 10.1016/j.meegid.2013.02.005.

NIZOLI, L. Q. et al. Immunogenicity and antigenicity of the recombinant EMA-1 protein of Theileria equi expressed in the yeast Pichia pastoris. Brazil. Journal Veterinary Parasitology, v.18, n.2, p.1-4, 2009. Disponível em: <http://www.scielo.br/scielo.php?pid=S 1984-296120090 00200001\&script=sci_arttext. $>$. Acesso em: 15 abr. 2013. doi:10.4322/rbpv.01802001.

OFFICE INTERNATIONAL DES EPIZOOTIES (OIE). Equine piroplasmosis. In: Manual of diagnostic and vaccines for terrestrial animals, 2008. CHAPTER 2.5.8. Disponível em: <http://www.oie.int/fileadmin/Home/eng/Health_standards/ tahm/2.05.08_EQUINE_PIROPLASMOSIS.PDF>. Acesso em: 05 fev. 2014.

OFFICE INTERNATIONAL DES EPIZOOTIES (OIE). Pruebas de diagnóstico prescritas y de sustitución para las enfermedades de la lista de la OIE, 2010. Disponível em: <http://www.oie.int/fileadmin/Home/esp/Health_ standards/tahc/2010/es_chapitre_1.1.3.htm>.Acesso em: 23 out. 2012 .

Ciência Rural, v.44, n.10, out, 2014. 
RAMPERSAD, J. et al. A field evaluation of PCR for the routine detection of Babesia equi in horses. Veterinary Parasitology, v.114, p.81-87, 2003. Disponível em: <http://www.ncbi.nlm.nih. gov/pubmed/12781470>. Acesso em: 03 maio 2013. doi: 10.1016/ S0304-4017(03) 00129-8.

SAMBROOK, J.; RUSSEL, D.W. Molecular cloning. A Laboratory Manual. New York: Cold Spring Harbor Laboratory, 2001. p.9.16-9.17

TANAKA, T. et al. Expression of Babesia equi merozoite antigen-2 by recombinant baculovirus and its use in the ELISA. International journal for Parasitology, v.29, p.1803-1808, 1999. Disponível em: <www.ncbi.nlm.nih.gov/ pubmed/10616926>. Acesso em: 15 abr. 2013. doi:10.1016/ S0020-7519(99)00146-0.

UILENBERG, G. Babesia - A historical overview. Veterinary Parasitology, v.138, p.3-10, 2006. Disponível em: <www.ncbi. nlm.nih.gov/pubmed/16513280>. Acesso em: 20 out. 2012. doi: 10.1016/j.vetpar.2006.01.035

UETI, M.W. et al. Expression of Equi merozoite Antigen 2 during development of Babesia equi in the midgut and salivary gland of the vector tick Boophilus microplus. Journal of Clinical Microbiology, v.41, p.5803-5809, 2003. Disponível em: <www. ncbi.nlm.nih.gov/pubmed/14662988>. Acesso em: 3 maio 2013. doi: 10.1128/JMC.41.12.5803-5809.2003. 